\title{
CONCEPÇÃO E PLANEJAMENTO DE ÁREAS INFANTIS DE PARQUES PÚBLICOS DA CIDADE DE RENNES NA FRANÇA
}

Recebido em: 04/04/2016

Aceito em: 17/12/2016

\author{
Daniella Tschöke Santanal \\ Simone Rechia ${ }^{2}$ \\ Universidade Federal do Paraná - UFPR \\ Curitiba - PR - Brasil \\ Aline Tschöke \\ Instituto Federal do Paraná \\ Paranaguá - PR - Brasil \\ Luize Moro ${ }^{4}$ \\ Karine do Rocio Vieira dos Santos ${ }^{5}$ \\ Emília Amélia Pinto Costa Rodrigues ${ }^{6}$ \\ Gabriela Cardoso Machado ${ }^{7}$ \\ Universidade Federal do Paraná - UFPR \\ Curitiba - PR - Brasil
}

RESUMO: Na cidade contemporânea as áreas infantis, espaços públicos destinados às brincadeiras das crianças, assumem um papel de importância na garantia do direito ao brincar na cidade. Esta pesquisa busca analisar as formas de organização e planejamento de espaços e equipamentos de três áreas destinadas às crianças de três parques públicos da cidade de Rennes, na França. Observações assistemáticas e participantes, registros fotográficos, análise de documentos públicos da cidade de Rennes e aplicação de questionário com o gestor responsável por estes espaços compuseram a metodologia. Observou-se que os espaços em Rennes são seguros, mantidos e possuem uma política de gestão. As áreas infantis constituem-se como importantes brechas do brincar infantil nas cidades e por isso estes espaços devem ser o mais atrativo, seguro e dinâmico, a fim de que possam atender ao menos uma parcela das necessidades das crianças.

PALAVRAS CHAVE: Atividades de Lazer. Jogos e Brinquedos. Parques Recreativos. Áreas Verdes.

\footnotetext{
${ }^{1}$ Mestre em Educação Física pela UFPR.

${ }^{2}$ Professora Pós-Doutora da UFPR.

${ }^{3}$ Doutora em Educação Física pela UFPR.

${ }^{4}$ Doutoranda em Educação Física pela UFPR.

${ }^{5}$ Mestre em Educação Física pela UFPR.

${ }^{6}$ Doutora em Educação Física pela UFPR.

${ }^{7}$ Mestre em Educação Física pela UFPR.
} 


\section{CONCEPTION AND PLANNING OF CHILDREN'S PLAYGROUNDS OF PUBLIC PARKS IN THE CITY OF RENNES IN FRANCE}

ABSTRACT: In the contemporary city playgrounds, public spaces for children to play, take on a role of importance in guaranteeing the right to play in the city. This research seeks to analyze the forms of organization and planning of spaces and equipment of three playgrounds of three public parks in the city of Rennes, in France. Participating and non-systematic observations, photographic records, analysis of public documents from the city of Rennes and the application of a questionnaire with the manager responsible for these spaces composed the methodology. It was observed that the spaces in Rennes are safe, maintained and have a management policy. The children's playgrounds are as important breaches of children's play in cities and so these spaces must be as attractive, safe and dynamic, so that they can attend at least a portion of the needs of children.

KEYWORDS: Leisure Activities. Play and Playthings. Parks, Recreational. Green Areas.

\section{Introdução}

Hoje às cidades vêm sendo atribuídos significados limitados e instrumentalizados. $\mathrm{O}$ espaço público urbano vem perdendo seu caráter multifuncional e resume-se cada vez mais a funções de circulação, “[...] as ruas e a maioria das praças das grandes cidades são concebidas, quase sempre, unicamente como locais de acesso e passagem" (MARCELLINO et al., 2007, p. 21). Somado a isto, o aumento da violência e da sensação de insegurança e medo, conduzem a um crescente esvaziamento dos espaços públicos por parte da população, de modo mais expressivo dos espaços de lazer, podendo este fato levar à falta de investimento do poder público ou ainda à apropriação destes locais pela iniciativa privada ${ }^{8}$.

Na contramão destas constatações, Marcellino et al. (2007, p.18) aponta que

Mesmo saqueada e esvaziada dos valores do encontro humano, a cidade, no entanto, não é eliminada. Ela resiste, à medida que o valor de uso do espaço não é eliminado de vez. E ele reaparece, entre outras

\footnotetext{
${ }^{8}$ Pesquisas do Grupo de Estudos e Pesquisa em Lazer, Espaço e Cidade (GEPLEC) coordenado pela Professora Dra. Simone Rechia apontam estas questões, a exemplo dos trabalhos de Tschoke (2010) e Assis (2014).
} 
possibilidades nas práticas de lazer, da perspectiva de desenvolvimento pessoal e social, do encontro e da convivencialidade, do corpo.

É nas experiências de lazer na cidade que os sujeitos podem desenvolver sua capacidade criativa com maior liberdade, podem significar sua emancipação quando as práticas são reflexivas e críticas. Esta forma profunda de vivenciar o lazer implica a necessidade de um espaço. Os espaços de lazer são

[...] considerados lugares de socialização citadina por excelência, de potencialização de identidades culturais, de possibilidades de estabelecer relações multiculturais e integração social, aspectos que fazem parte de uma comunidade de convivência (RECHIA; BÉTRAN, 2010, p. 184).

Verifica-se hoje que grande parte das crianças desenvolve suas brincadeiras em espaços institucionalizados como casa, escola, condomínio, clubes (RECHIA, 2009; WRIDT, 2004; TONUCCI, 1996) sendo que “[...] a prática do brincar tradicional, o brincar livre, em quintais e ruas está se ausentando do mundo das crianças" (MORO, 2012, p. 13). Alterações na organização social do tempo, a carga horária de trabalho dos pais, as questões urbanas, a evolução e o acesso ampliado às tecnologias, podem figurar entre os motivos desta migração do público infantil dos espaços públicos para os privados ou institucionalizados.

O brincar é a essência de ser criança. É por meio da brincadeira que a criança apreende o mundo, compreende e faz-se a si mesma, constrói sua identidade, experimenta, supera desafios e testa limites, se expressa, se expande, interage, desenvolve habilidades (motoras, cognitivas, emocionais, imaginativas), autonomia, possibilidades de criação. O brincar oportuniza vivenciar a dimensão lúdica e é uma atividade que exige concentração e dedicação para sua construção. 
Ferronato e Batista $(2013$, p.128) afirmam que "[...] o brincar consiste no direito de liberdade de ação da criança no sentido que ela tem a possibilidade de escolha e de ação de acordo com suas motivações próprias". Sabemos que tais motivações e ações das crianças são influenciadas pelo ambiente e pelas pessoas ao seu redor, mesmo assim, “[...] brincando, a criança aprende a ser livre harmonizando o seu mundo interior nas mais variadas composições com o mundo exterior. $\mathrm{O}$ direito de brincar como um direito de liberdade é equilíbrio e felicidade” (idem, p. 129).

Dos espaços e equipamentos particularmente pensados para práticas de lazer, pode-se destacar os locais destinados às brincadeiras infantis, as áreas infantis, também conhecidas como parquinhos, playgrounds, ou ainda, aires de jeux, planejadas especificamente para proporcionar vivências lúdicas para as crianças.

Dessa forma, constatando a importância do papel do brincar da criança, tendo em vista a potencialidade que pode ser atribuída às áreas infantis enquanto espaços que oportunizam a ampliação desta dimensão lúdica, além do papel das políticas públicas na implementação destes locais, esta pesquisa teve como objetivo analisar as formas de organização e planejamento de espaços e equipamentos de três áreas infantis presentes em três parques públicos da cidade de Rennes ${ }^{9}$, na França.

\footnotetext{
${ }^{9}$ A cidade de Rennes localiza-se na região da Bretanha, noroeste da França, e situa-se a aproximadamente 300 quilômetros da capital, Paris. É a maior cidade da região da Bretanha e a $11^{\mathrm{a}}$ cidade mais populosa da França. De acordo com dados do Instituto Nacional de Estatística e Estudos Econômicos (INSEE) da França, Rennes conta com uma população de 207.178 habitantes, sendo 97.794 homens e 109.384 mulheres (INSEE, 2010).
} 
Aline Tschöke, Luize Moro, Karine do Rocio V. dos Santos,

Emília Amélia Pinto C. Rodrigues e Gabriela C. Machado

\section{Caminhos Percorridos}

Esta pesquisa de abordagem qualitativa investigou a organização e o planejamento dos espaços e equipamentos de áreas infantis integradas a parques públicos da cidade de Rennes, na França.

Por meio de observações assistemáticas, realizadas entre os meses de janeiro e maio de 2012, foi analisada a organização de três áreas infantis específicas de três parques públicos da cidade - parques Thabor (o parque mais conhecido da cidade), Maurepas (inserido em uma região da cidade que possui suas porções escolares e universitárias) e Bréquigny (parque paisagístico). Registros fotográficos também compuseram as observações dos locais.

Foi realizada igualmente uma pesquisa documental a partir de arquivos públicos disponíveis online, a fim de encontrar dados que auxiliassem na análise do processo de planejamento destas áreas infantis. Encontramos documentos tais como o (1) Plano Local de Urbanismo da Cidade (PLU), documento que estabelece um projeto global de urbanismo e desenvolvimento e determina as regras gerais de utilização do solo sobre o território considerado; o (2) Caderno de Prescrições Gerais do Espaço Público $^{10}$, que reúne as prescrições técnicas referentes à criação ou requalificação dos espaços públicos desta cidade, composto por diferentes livretos técnicos, cada qual abordando uma temática específica e o (3) Guia de Manutenção dos parques e jardins de Rennes, composto por três partes: especificidades da cidade, os códigos e classificações das áreas verdes e fichas técnicas dos trabalhos específicos a serem realizados (buscou-se localizar palavras-chave como: aires de jeux, terrains de jeux,

\footnotetext{
${ }^{10} \mathrm{O}$ acesso foi realizado mediante cadastro no site http://www.espacepublic.rennes.fr/, com posterior aprovação e seguindo determinadas cláusulas de utilização. Este documento é composto por livretos transversais e livretos temáticos. Foram consultados os livretos transversais de Espaços Verdes e Mobiliário Urbano.
} 
jeux, plaines de jeux, que significam "áreas de jogo", "terrenos de jogo", “jogo", "planícies de jogo", que fazem referência às áreas infantis). O site oficial da cidade de Rennes $^{11}$, que apresenta diversas informações sobre a mesma (atualidades, políticas públicas, informações práticas), também foi consultado.

Além disso, foi estabelecido contato por meio de telefone e e-mail com um dos integrantes da Direção de Jardins da cidade, órgão responsável pela manutenção dos parques e jardins dos setores centro e leste e das áreas infantis. Para o responsável foi enviado via e-mail um questionário composto por perguntas abertas, relativas à manutenção, equipamentos e especificidades das áreas infantis. $\mathrm{O}$ mesmo foi respondido e retornado igualmente por e-mail para as pesquisadoras.

Após estes passos, realizamos uma triangulação dos dados, procurando relacionar o que foi observado e registrado, com os dados obtidos por meio dos documentos conectando, por fim, as informações fornecidas pelo gestor responsável.

\section{Descobrindo as Áreas Infantis de Rennes: Aspectos Gerenciais e Estruturais}

\section{Gestão}

De acordo com passagem do Caderno de Prescrições Gerais do Espaço Público, em seu livreto Espaços Verdes, as áreas infantis são entendidas como "[...] toda zona especialmente organizada e equipada para ser utilizada, de forma coletiva, por crianças para fins de brincar [...]” (RENNESa, 2008, p. 48, tradução nossa).

Com relação à política de gestão das áreas infantis,

Há vários anos, a cidade de Rennes instala e mantém as áreas infantis nos parques, jardins e espaços verdes dos bairros a fim de oferecer ao maior número de pessoas a possibilidade de desfrutar destes equipamentos. Sendo estes equipamentos utilizados principalmente

\footnotetext{
${ }^{11}$ www.metropole.rennes.fr.
} 
pelos habitantes do bairro onde estão implantados, sua localização não pode se limitar aos parques, jardins e espaços verdes públicos. Para garantir uma cobertura homogênea e maior possível destes equipamentos na cidade, toda coeur d'îlot bâti ${ }^{12}$ comportará uma área de jogo adaptada em função do número de crianças e suas faixas etárias (RENNESa, 2008, p.48, tradução e grifo nossos).

O Responsável de Manutenção dos espaços verdes dos setores centro e leste da cidade, também responsável pelas áreas infantis, afirma que a política norteadora é a de buscar "[...] propor áreas infantis de qualidade e suficientemente ricas à cerca de $300 \mathrm{a}$ $500 \mathrm{~m}$ de cada habitação da cidade. Até o momento, mais de $90 \%$ da cidade responde a este critério".

Como afirmam Rechia e Tschoke (2012, p. 268)

[...] os espaços públicos de lazer da cidade podem ser considerados adequados ao lazer infantil, desde que sejam próximos da residência das crianças e possibilitem a vivência de práticas lúdicas. Essa questão está relacionada com o planejamento e a manutenção desses locais.

Além disso, Jacobs (2000, p. 88) ressalta a necessidade das crianças da cidade poderem usufruir de uma boa quantidade de locais onde possam brincar e aprender. Segunda a autora, "[...] precisam, entre outras coisas, de oportunidades para praticar todo tipo de esporte e exercitar a destreza física- e oportunidades mais acessíveis do que aquelas de que desfrutam na maior parte dos casos". A autora ainda complementa a necessidade desses locais perto de casa e ao ar livre.

Desta forma percebemos que a administração pública pretende abranger grande parte da cidade com áreas infantis, estando estas presentes em parques e jardins, mas também nas regiões centrais dos blocos urbanos (que apresentem certo número de crianças) e adaptadas às faixas etárias observadas do entorno, garantindo o direito de

\footnotetext{
${ }^{12}$ Coeur d'îlot bâti: expressão que designa a parte interna de um bloco urbano. Pode ser constituída de um espaço livre/fechado ou de um espaço verde, mas pode igualmente ser urbanizada.
} 
brincar em locais próximos da sua residência, facilitando de modo considerável a utilização destes espaços e a realização de práticas corporais pelo público infantil.

No documento intitulado "Prêmio da cidade lúdica 2005" afirma-se que

A política da cidade de Rennes referente às áreas infantis integra-se totalmente nas políticas mais amplas de organização dos espaços públicos. Ela se traduz pela vontade de oferecer várias áreas infantis por um lado, mas por outro multiplicar os usos integrando a variedade de funções lúdicas possíveis, os diferentes públicos a acolher (faixas etárias, mas igualmente levando em conta as crianças com mobilidade reduzida) (RENNESb, 2005, p. 4, tradução e grifo nossos).

Verificamos assim a intenção do poder público em ampliar o número de crianças que desfrutam destes espaços, ao oferecê-los em várias áreas da cidade, mas também se percebe a preocupação em variar suas "funções lúdicas", ou seja, proporcionar equipamentos que estejam de acordo com o público alvo/faixa etária predominante que se apropriará do espaço, bem como promover diferentes possibilidades de práticas corporais a partir de uma variedade de equipamentos.

Somado a isso, este documento aponta o fato da cidade levar em consideração as necessidades em jogo na organização do espaço público e que esta reflexão é conduzida com bastante antecedência pelo desenvolvedor responsável, em consulta com os habitantes. Ainda completa registrando que a evolução permanente da população no interior de um bairro, sub-bairro ou bloco urbano necessita de uma reavaliação regular destas organizações, sendo que uma real proximidade com os habitantes ${ }^{13}$ permite levar

\footnotetext{
${ }^{13}$ Para promover esta maior aproximação habitante-gestão, a cidade conta com 6 direções e 13 conselhos de bairro. As direções reúnem, cada uma, dois bairros e estão localizadas no centro dos mesmos. Esta territorialização foi idealizada com o objetivo de permitir maior acessibilidade e proximidade entre os habitantes e a administração, a fim de melhor identificar as necessidades e expectativas dos moradores e prestar serviços mais responsivos, por meio, por exemplo, de pesquisas e da realização de assembleias com os moradores.
} 
em conta estas evoluções, sendo que este contato influenciará a condução de políticas futuras, tendo em vista o modo como a comunidade vai se desenvolvendo.

Neste mesmo documento, Rennes (2005b) apresenta os meios para colocar em prática esta política para as áreas infantis, os quais consistem em: “[...] conhecer, manter e fazer evoluir o patrimônio". No que se refere ao processo de implementação das áreas infantis, alguns passos são seguidos: avaliação das necessidades, o projeto, o comando e os trabalhos. Em cada uma destas fases há maior ou menor presença de diferentes atores sociais, mas cada um tem a possibilidade de participação no projeto (seja na avaliação das necessidades e elaboração do projeto, na colaboração entre habitantes, arquitetos e planejadores, no comando e trabalhos entre planejadores, compradores, empresas e funcionários da prefeitura).

Nos documentos analisados, também encontramos algumas informações referentes às formas de gestão da estrutura das áreas infantis. De acordo com o Guia de Manutenção de parques e jardins da cidade (RENNESc, 2005), as superfícies das áreas infantis e zonas de uso específico (descanso, pique-nique, bocha) devem conservar uma superfície de cascalho. Desta forma, de acordo com a cidade

\begin{abstract}
Deve-se, portanto, definir um perímetro claro em torno dos equipamentos das áreas infantis e usos específicos, em que o processamento é o mesmo do utilizado nos caminhos ${ }^{14}$. Os equipamentos podem ser agrupados em conjunto a fim de definir mais claramente a área do parque infantil. Será necessário estar atento quanto à conformidade com as normas em vigor (distâncias de segurança, materiais de amortecimento[...]) (RENNESc, 2005, p. 31, tradução nossa).
\end{abstract}

Desta forma, eles estabelecem o cascalho como superfície das áreas infantis, mesmo material utilizado nos caminhos e vias dos parques. Esta passagem mostra

\footnotetext{
${ }^{14}$ Esta passagem refere-se aos caminhos utilizados no interior dos parques, cujas vias internas também são feitas de cascalho.
} 
também o conhecimento e a necessidade em estar de acordo com a regulamentação específica existente para os espaços.

Ainda encontramos algumas considerações com relação à manutenção dos espaços verdes próximos às áreas infantis, referentes à frequência da poda de árvores, corte de grama, retirada de ervas daninhas.

Nos documentos, não foram encontradas informações a respeito dos modelos dos equipamentos que devem compor as áreas infantis. De acordo com resposta do gestor responsável, com relação à escolha exata do equipamento em si, não há participação da população. A implementação e a compra dos equipamentos entram no processo de licitação e concorrência, aberto ao mercado público. Mas ele reitera que “[...] quando um espaço é restaurado ou requalificado, existem reuniões de consulta com os habitantes e usuários que permitem traçar as necessidades e os elementos lúdicos a prever". Percebemos então que a participação efetiva da comunidade interessada está relacionada à consulta, reuniões e decisões a respeito das ações a serem tomadas, cabendo aos responsáveis do poder público da cidade a efetivação destas ações.

Em relação aos critérios de escolha dos equipamentos, a resposta do gestor indica que se leva em conta: - A durabilidade: materiais, concepção;- As qualidades lúdicas propostas;- A estética, a fim de melhor se ajustar às características do local.

Em relação ao acesso, como as áreas infantis analisadas neste estudo estão particularmente inseridas em parques públicos sua possibilidade de uso segue o horário de funcionamento dos mesmos, sendo este diferenciado no verão e no inverno. As áreas infantis localizadas nos bairros, sub-bairros e demais blocos urbanos ficam disponíveis à utilização sem restrição de horários. 
De modo geral, verificamos uma preocupação global com as áreas infantis, no sentido de proporcionar brinquedos duráveis, seguros, adequados ao local onde estão inseridos, em relação à faixa etária das crianças e às particularidades físicas da região. É interessante destacar que as "qualidades lúdicas" do equipamento também são analisadas, ou seja, há o cuidado de se pensar os tipos de brincadeiras e movimentos que o equipamento selecionado estará proporcionando.

\section{Estrutura}

As três áreas infantis pesquisadas apresentam suas particularidades, principalmente em função dos parques onde estão localizadas. A área infantil do parque do Thabor foi inaugurada em 1968 e é composta pelos seguintes equipamentos ${ }^{15}$ :

TABELA 1 - Lista de equipamentos da área infantil do parque do thabor e suas respectivas faixas etárias indicativas

\begin{tabular}{|l|l|}
\hline EQUIPAMENTO & IDADE \\
\hline Caixa de areia & 2 a 8 anos \\
\hline Estruturas multifuncionais & 6 a 16 anos \\
\hline 2 Escorregadores & 4 a 12 anos \\
\hline Brinquedo de mola & 2 a 4 anos \\
\hline 3 Brinquedos de mola & 2 a 6 anos \\
\hline Brinquedo de mola & 2 a 12 anos \\
\hline
\end{tabular}

Esta área infantil localiza-se entre o jardim botânico e o jardim paisagístico do parque. Situa-se próxima aos banheiros e possui bancos instalados sob árvores, como destacado na Figura 1, permitindo aos pais ou responsáveis que acompanham as crianças manterem um olhar atento sobre elas. Os equipamentos encontram-se todos no mesmo ambiente, porém são destacados por blocos de pedra dispostos em forma

\footnotetext{
${ }^{15}$ Segundo dados do Plano Interativo de Rennes (Cidade e região Metropolitana) (2011). Disponível em: <http://www.geo.rennesmetropole.fr/>. Acesso em: 20/11/2013.
} 
Daniella T. Santana, Simone Rechia, Concepção e Planejamento de Áreas Infantis... Aline Tschöke, Luize Moro, Karine do Rocio V. dos Santos, Emília Amélia Pinto C. Rodrigues e Gabriela C. Machado

circular Figura 2 e possibilitam seu uso por crianças e adolescentes de várias idades, contemplando dos 2 aos 16 anos.

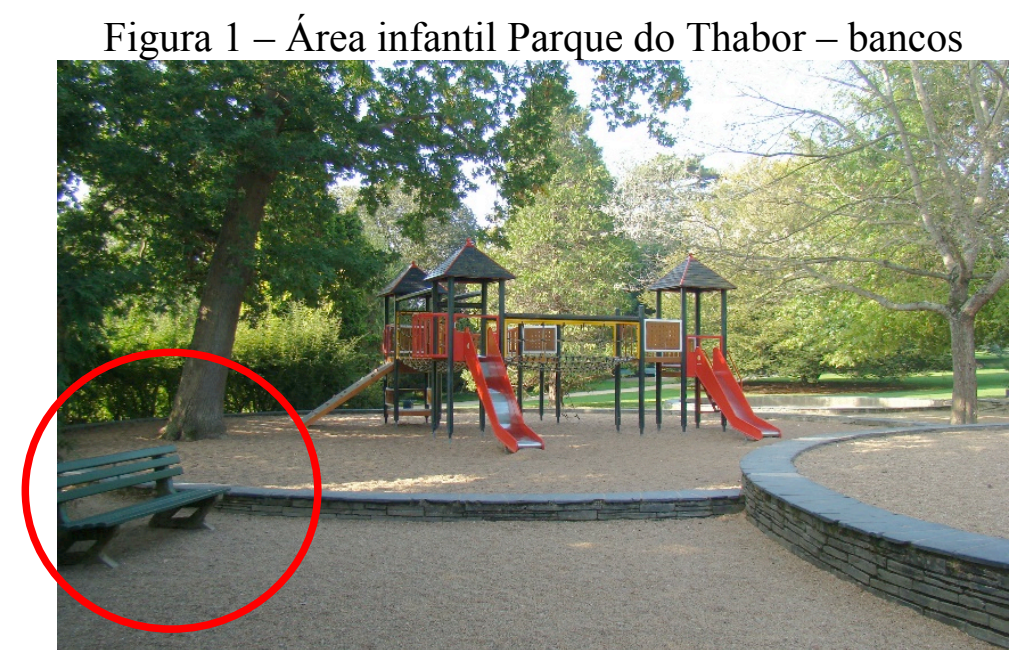

Fonte: Wikimedia, $2013^{16}$.

Figura 2 - Área infantil Parque do Thabor - divisão dos equipamentos com pedras dispostas em formato circular

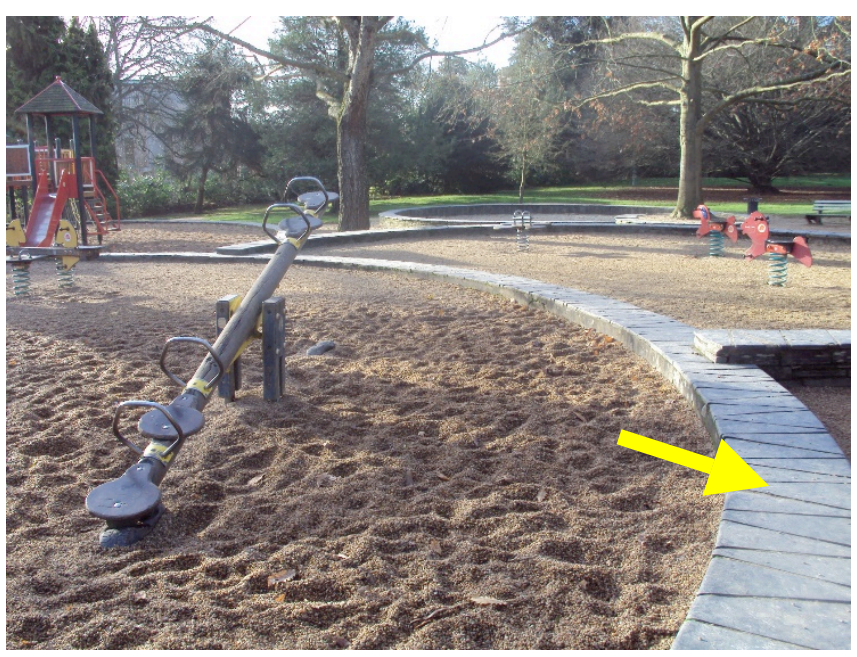

Fonte: Arquivo pessoal, 2012.

As Figuras 3 e 4, mostram exemplos de brinquedos encontrados nesta área infantil, como brinquedos de mola.

16 Disponível em: < http://commons.wikimedia.org/wiki/File:Thabor_Aire_de_Jeu.JPG $>$. Acesso em: $16 / 11 / 2013$. 
Aline Tschöke, Luize Moro, Karine do Rocio V. dos Santos,

Emília Amélia Pinto C. Rodrigues e Gabriela C. Machado

Figuras 3 e 4 - Área infantil Parque do Thabor - exemplo de brinquedos de mola.
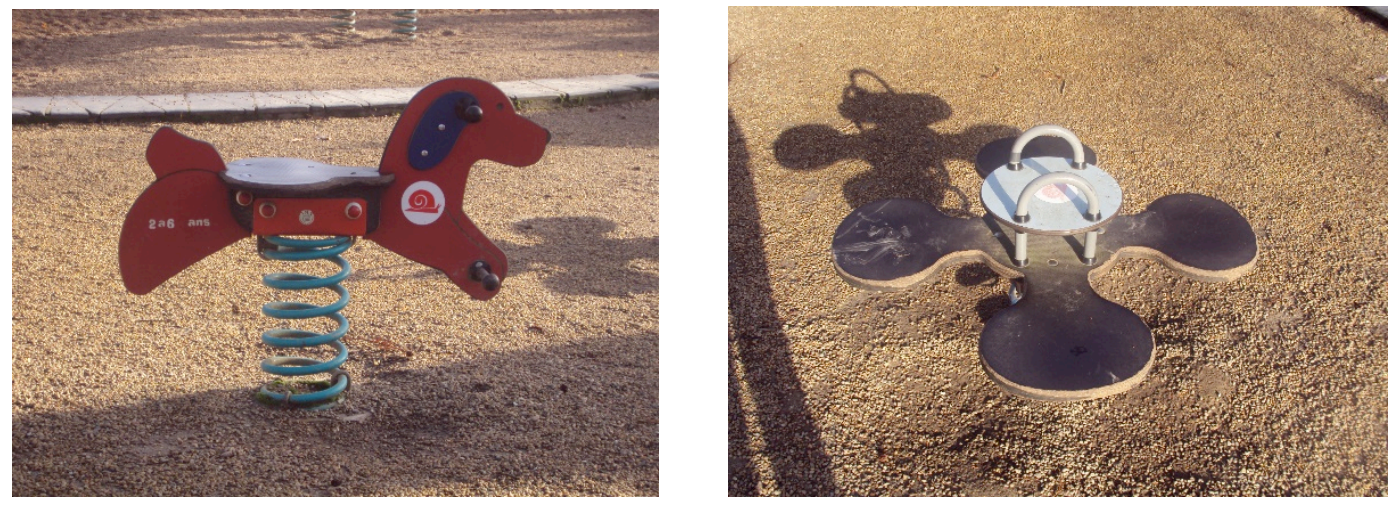

Fonte: Arquivo pessoal, 2012.

Os equipamentos e a área infantil como um todo são bem delimitados. Apresenta brinquedos variados, que contemplam uma faixa etária considerável e possibilitam brincadeiras individuais e/ou coletivas.

A área infantil do parque de Maurepas é composta pelos seguintes equipamentos:

TABELA 2 - Lista de equipamentos da área infantil do Parque de Maurepas e suas respectivas faixas etárias indicativas

\begin{tabular}{|l|l|}
\hline EQUIPAMENTO & IDADE \\
\hline Brinquedo de rotação e translação & 3 a 10 anos \\
\hline 2 Brinquedos de rotação e translação & 6 a 14 anos \\
\hline 2 Escorregadores & 4 a 12 anos \\
\hline 2 Brinquedos de mola & 2 a 5 anos \\
\hline 2 Balanços & 3 a 12 anos \\
\hline 3 Brinquedos de mola & 2 a 8 anos \\
\hline 3 Brinquedos de mola & 2 a 10 anos \\
\hline 2 Brinquedos de mola & 3 a 8 anos \\
\hline Brinquedo de mola & 4 a 10 anos \\
\hline Brinquedo de mola & 5 a 8 anos \\
\hline Balanços & 1 a 6 anos \\
\hline Balanço & 3 a 12 anos \\
\hline Balanço & 3 a 10 anos \\
\hline 2 Caixas de areia & 2 a 8 anos \\
\hline Estruturas multifuncionais & 1 a 4 anos \\
\hline $\begin{array}{l}\text { Pista com sinalização rodoviária em miniatura - adaptada } \\
\text { para bicicleta, patins, patinete. }\end{array}$ & ------- \\
\hline Pista com obstáculos - bicicleta, patinete, skate, patins. & ------- \\
\hline
\end{tabular}


Aline Tschöke, Luize Moro, Karine do Rocio V. dos Santos,

Emília Amélia Pinto C. Rodrigues e Gabriela C. Machado

Esta área infantil possui maiores dimensões se comparada às dos demais parques analisados. Também conta com maior quantidade e diversidade de equipamentos, com destaque para a pista com sinalização rodoviária em miniatura Figura 5, cujo circuito se dá em torno dos demais equipamentos e da caixa de areia, e a pista com obstáculos Figuras 6 e 7, situada próximo a um vasto gramado. Além disso, possui equipamentos não encontrados ou encontrados em menor número nos outros parques, como os equipamentos de rotação e translação (FIGURA 10). As pistas e demais equipamentos infantis também possuem bancos próximos. A área infantil atende uma parcela variada de idades, mas apresenta idade máxima de 14 anos para uso de determinados equipamentos.

Figura 5 - Área infantil Parque de Maurepas - pista com sinalização rodoviária em miniatura

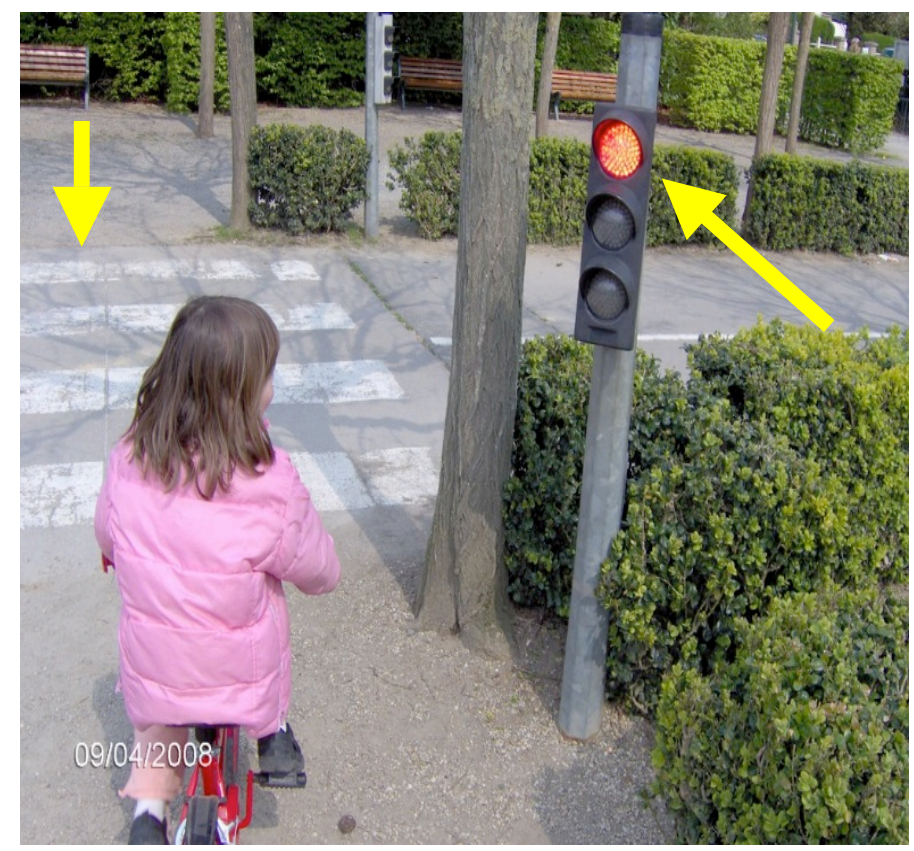

Fonte: Panoramio, s/d ${ }^{17}$.

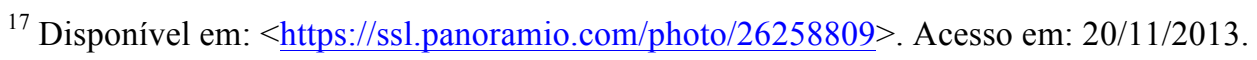


Daniella T. Santana, Simone Rechia, Concepção e Planejamento de Áreas Infantis...

Aline Tschöke, Luize Moro, Karine do Rocio V. dos Santos,

Emília Amélia Pinto C. Rodrigues e Gabriela C. Machado

Figuras 6 e 7 - Área infantil Parque de Maurepas - pista com obstáculos

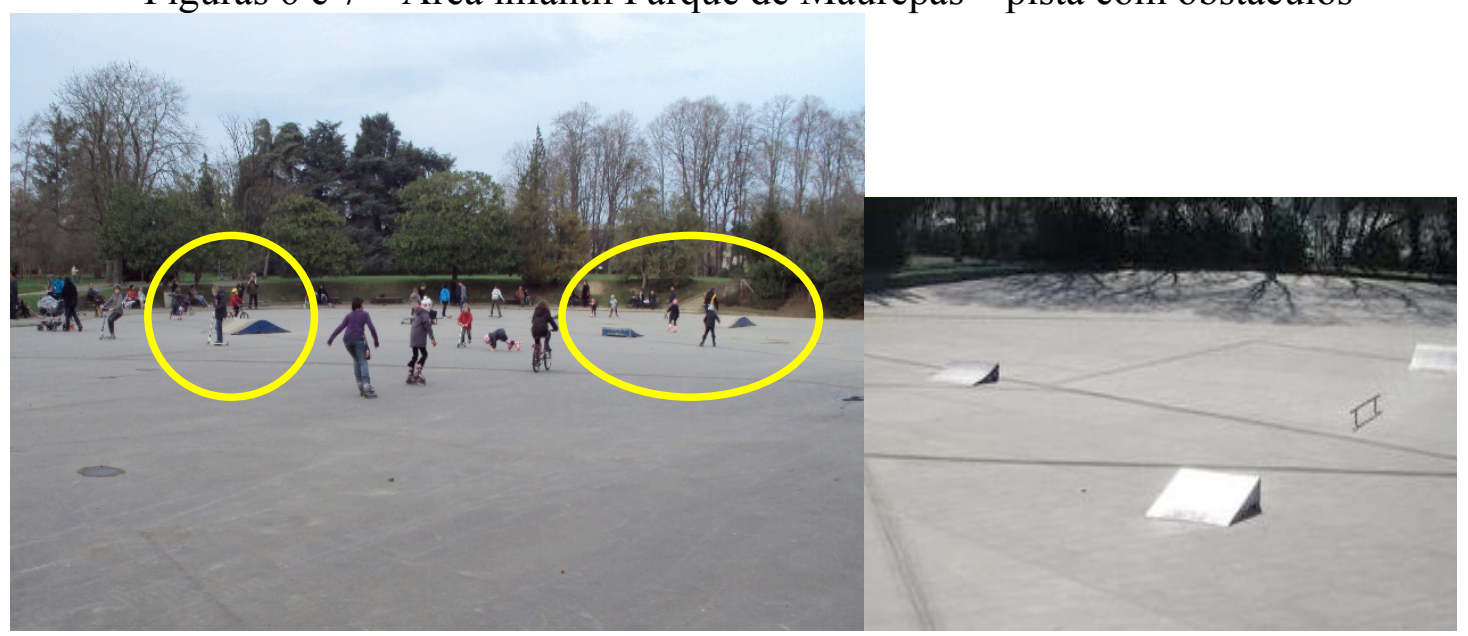

Fonte: Arquivo pessoal, 2012 e Bretagne tours, $2009^{18}$.

As Figuras 8, 9 e 10 mostram exemplos de equipamentos e brinquedos encontrados nesta área infantil, como gangorras, gira-giras, balanços, escorregadores (de formatos diferentes), dentre outros.

Figuras 8 e 9 - Área infantil Parque de Maurepas - exemplos de equipamento
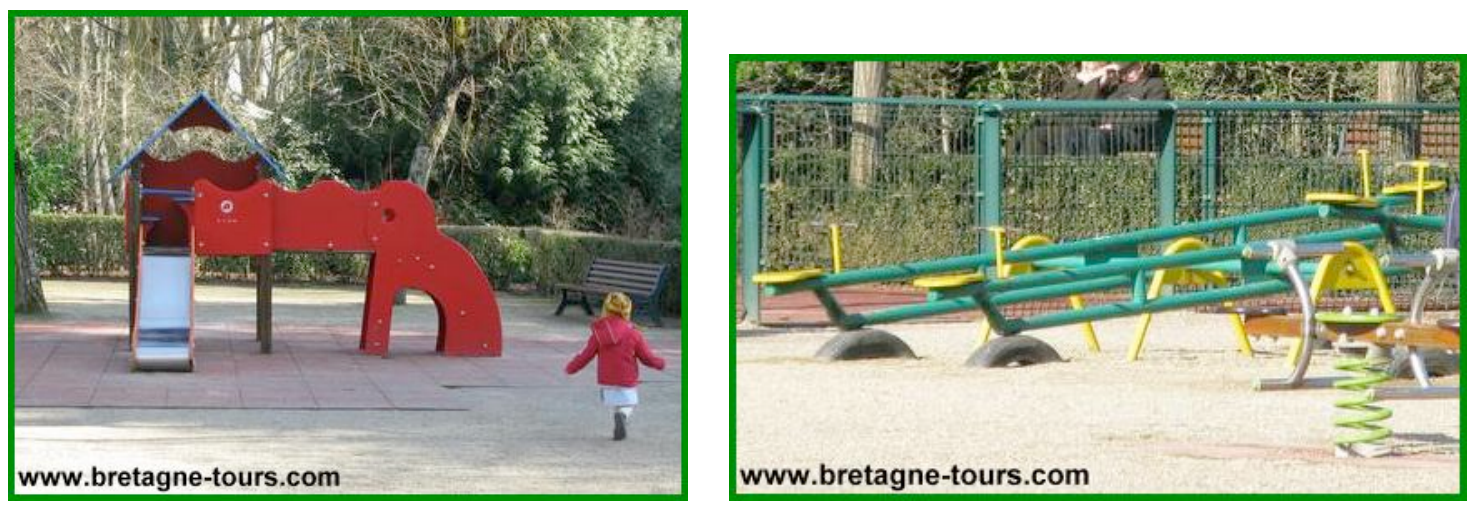

Fonte: Bretagne tours, $2009^{19}$.

18 Disponível em: <http://www.bretagne-tours.com/index.php/115-le-parc-de-maurepas-a-rennesbretagne-pour-les-enfants-de-7-mois-a-77-ans $>$. Acesso em: 10/11/2013.

19 Disponível em: <http://www.bretagne-tours.com/index.php/115-le-parc-de-maurepas-a-rennesbretagne-pour-les-enfants-de-7-mois-a-77-ans $>$. Acesso em: 10/11/2013. 
Daniella T. Santana, Simone Rechia, Concepção e Planejamento de Áreas Infantis...

Aline Tschöke, Luize Moro, Karine do Rocio V. dos Santos,

Emília Amélia Pinto C. Rodrigues e Gabriela C. Machado

Figura 10 - Área infantil Parque de Maurepas - exemplos de equipamento
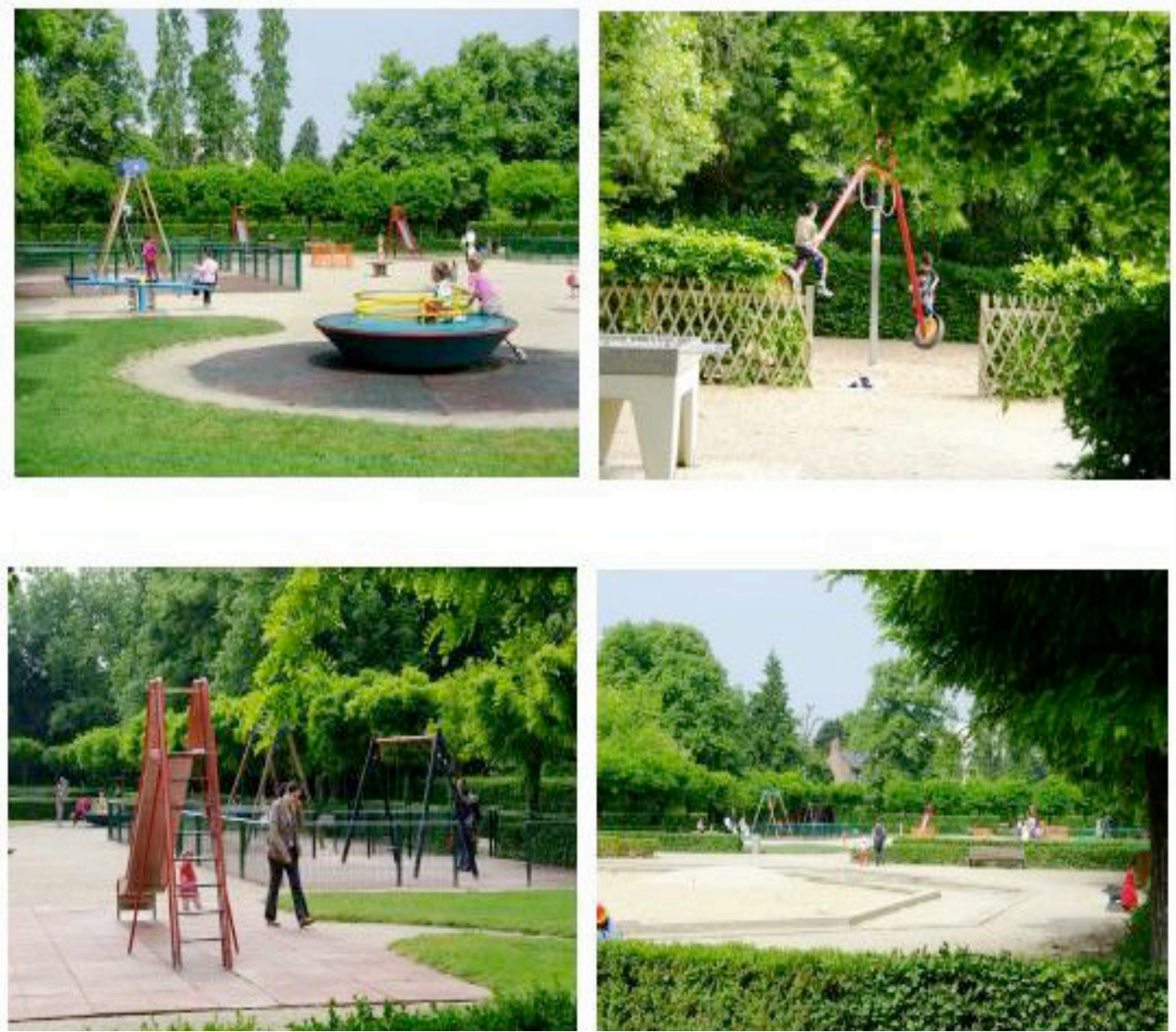

Fonte: Université Rennes $2, \mathrm{~s} / \mathrm{d}^{20}$.

É uma vasta área infantil muito utilizada pelas crianças, e que oferece uma gama bem diversificada de brinquedos, que possibilitam diferentes formas de movimentação corporal.

A área infantil do parque de Bréquigny é composta pelos seguintes equipamentos:

\footnotetext{
${ }^{20}$ Disponível em: <http://www.sites.univ-rennes2.fr/reso/espenf/spip.php?article108\#outil_sommaire_1>.
} Acesso em: 15/11/2013. 
TABELA 3 - Lista de equipamentos da área infantil do Parque de Bréquigny e suas respectivas faixas etárias indicativas

\begin{tabular}{|l|l|}
\hline EQUIPAMENTO & IDADE \\
\hline Estruturas multifuncionais & 3 a 16 anos \\
\hline Estruturas multifuncionais & 5 a 12 anos \\
\hline 2 Balanços & 3 a 16 anos \\
\hline 2 Balanços & 3 a 12 anos \\
\hline 2 Brinquedos de mola & 3 a 8 anos \\
\hline 2 Brinquedos de mola & 2 a 5 anos \\
\hline Brinquedo de rotação e translação & 3 a 10 anos \\
\hline 2 Escorregadores & 4 a 12 anos \\
\hline
\end{tabular}

Esta área infantil pode ser considerada de dimensão intermediária em relação às dos outros dois parques já analisados. Foi a única área infantil que apresentou o equipamento da Figura 11 em formato individualizado (estrutura em Rennes denominada de multifuncional, porém aqui conhecida como "trepa-trepa"). Nas demais áreas não foram observados trepa-trepas, apenas brinquedos de escalar integrados às outras estruturas multifuncionais (FIGURA 12). Apenas esta área infantil apresentou também um local próximo coberto para brincadeira (FIGURA 13 ${ }^{21}$. Próximas à área infantil também existem duas mesas de ping-pong ${ }^{22}$ e um pebolim. A Figura 14 mostra um exemplo de equipamentos encontrados.

\footnotetext{
${ }^{21}$ Nas outras duas áreas infantis a sombra era gerada pela grande quantidade de árvores presentes no entorno.

${ }^{22}$ No parque do Thabor também foi encontrada uma mesa de ping-pong, porém situada em outro local do parque, sem integração com a área infantil.
} 
Daniella T. Santana, Simone Rechia, Concepção e Planejamento de Áreas Infantis...

Aline Tschöke, Luize Moro, Karine do Rocio V. dos Santos,

Emília Amélia Pinto C. Rodrigues e Gabriela C. Machado

Figuras 11 e 12 - Área infantil Parque de Bréquigny - estruturas multifuncionais (a primeira conhecida aqui como trepa-trepa). destaque para o brinquedo de escalar integrado

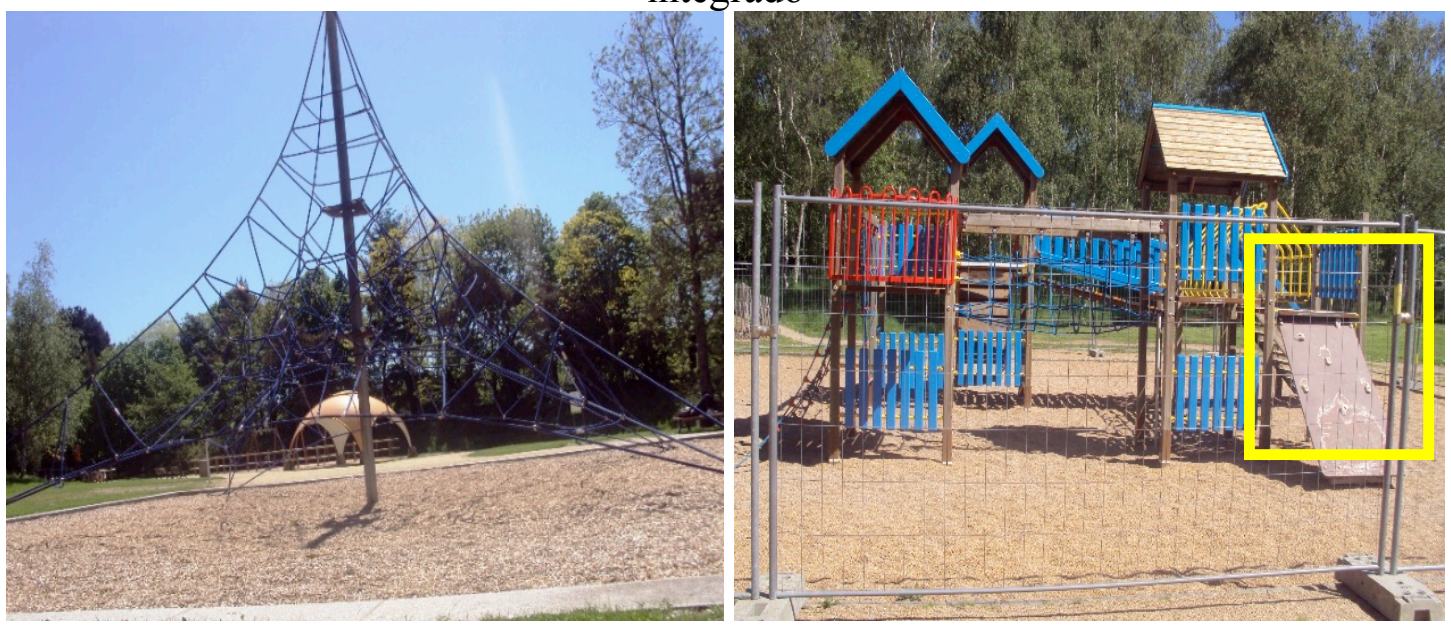

Fonte: Arquivo pessoal, 2012.

Figura 13 - Área infantil Parque de Bréquigny - área coberta

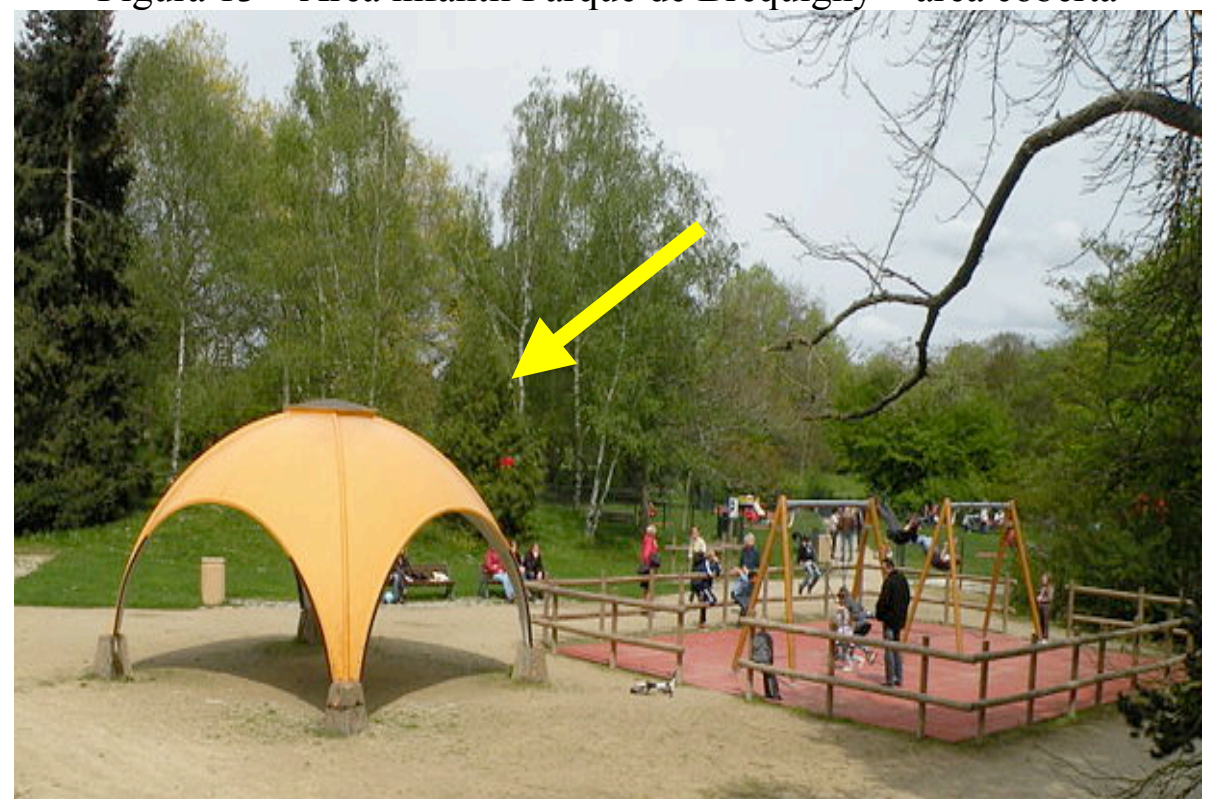

Fonte: Arquivo pessoal, 2012. 
Aline Tschöke, Luize Moro, Karine do Rocio V. dos Santos,

Emília Amélia Pinto C. Rodrigues e Gabriela C. Machado

Figura 14 - Área infantil Parque de Bréquigny - exemplos de equipamento

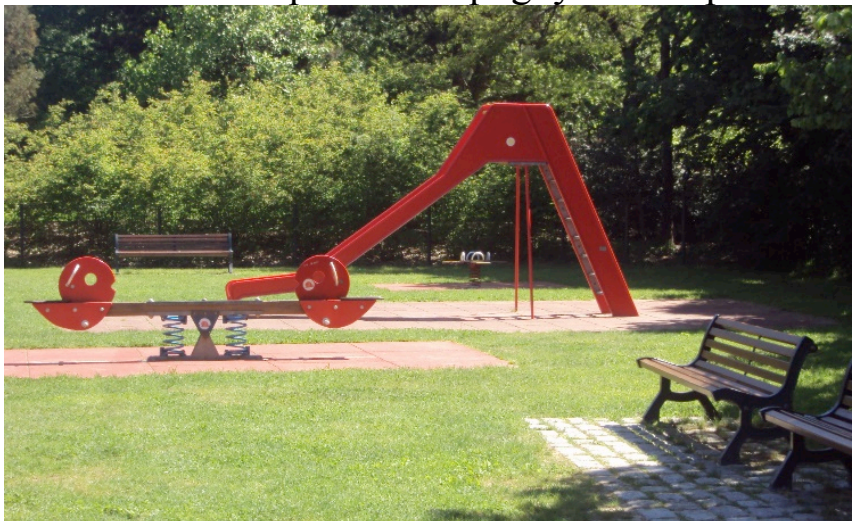

Fonte: Arquivo pessoal, 2012.

Esta área infantil apresenta equipamentos semelhantes e diferenciados em relação às demais áreas analisadas. Também proporciona às crianças um contato mais aproximado com a natureza, abundante no seu entorno.

\section{Relação entre as Áreas Infantis e os Bairros}

A primeira área infantil analisada situa-se no parque do Thabor, localizado na região central da cidade. De característica essencialmente contemplativa, é um dos parques mais conhecidos da cidade. De acordo com o plano interativo de Rennes ${ }^{23}$ este parque

[...] faz parte do patrimônio rennais [da cidade] com seus magníficos jardins à francesa, fontes e cascatas, suas árvores raras, estátuas, jardim de rosas e jardim botânico... É patrimônio da cidade de Rennes desde 1802. É um jardim paisagístico criado para contemplação em 1866 por Denis Bühler, paisagista parisiense. Possui uma superfície de 10,3 hectares. Equipado com área infantil, coreto, bar-restaurante acessível aos deficientes, carrossel (GEORENNESMETROPOLE, 2013, tradução e grifo nossos).

\footnotetext{
${ }^{23}$ Disponível em: <http://www.geo.rennesmetropole.fr/>. Acesso em: 01/11/2013. O Plano Interativo de Rennes (Cidade e Região Metropolitana) é uma cartografia interativa de localização de equipamentos, trabalhos, espaços verdes, estacionamentos, criada a fim de melhor situar os habitantes com relação à localização dos serviços da cidade de Rennes e região metropolitana.
} 
A segunda área infantil analisada localiza-se no parque de Maurepas, inserido em uma região da cidade que possui suas porções escolares e universitárias, mas que se apresenta fundamentalmente residencial, composta em sua grande parte por diversos conjuntos habitacionais. Criado em 1936 por Moser, é o primeiro parque higienista de Rennes (RENNESc, 2005), possui uma superfície de 6,1 hectares, com $206 \mathrm{~m}^{2}$ de roseiras e 650 árvores. Ele “[...] representa a transição entre jardins paisagísticos destinados à contemplação e os parques atuais concebidos também para o lazer" (RENNESd, 2004, p.186, tradução nossa). Possui uma paisagem enriquecida e plantas esculturadas.

Considerado o "paraíso das crianças", o parque de Maurepas "[...] foi criado para que as crianças possam se divertir livremente e aproveitar os diferentes jogos instalados e colocados gratuitamente à sua disposição" (L'OUEST ÉCLAIR, 26 julho 1939, tradução nossa), apresentando as várias estruturas destinadas às crianças (área infantil, pista com sinalização rodoviária em miniatura para bicicletas e patinetes e pista com obstáculos para bicicletas, patinetes, rollers e skates, também possui carrossel, gramados autorizados $\left.{ }^{24}\right)$.

Por fim, a terceira área infantil situa-se no parque de Bréquigny, parque paisagístico à inglesa que possui 18,9 hectares. Segundo o PLU da cidade “[...] é um parque destinado ao descanso, mas associa sua função de uso no lazer à de decoração e interesse hortícola. É composto de uma relativa diversidade vegetal. É um vasto parque de bairro, muito estruturado, para todo o sul da cidade" (RENNES, 2004d, p.186, tradução nossa). É também destinado à caminhada, com uma pista de Cooper de 1,9 $\mathrm{km}$, e ao jogo, com áreas infantis e piscina para crianças, pebolim e mesas de ping-

\footnotetext{
${ }^{24} \mathrm{Na}$ França, em alguns parques, não se pode pisar em toda a grama, há sinalização nos gramados em que é permitido pisar.
} 
pong. Conta com gramados autorizados, instalações de piquenique, áreas de descanso e área destinada à prática de exercícios físicos. Ao Leste apresenta uma área mais natural e um pântano.

O Caderno de Prescrições Gerais do Espaço Público de Rennes afirma que se busca identificar para os espaços diferentes categorias de usuários (crianças, adolescentes, adultos, idosos) e formas de usos. Para as áreas infantis são propostas áreas adaptadas às faixas etárias e às pessoas com mobilidade reduzida (RENNES, 2008a, p. 21, tradução nossa).

O Guia de Manutenção nos diz que

Cada parque rennais [da cidade de Rennes] foi concebido em função de um comando específico dos governos: se em 1867 o Thabor propunha à sociedade local de desfilar em torno de um quadro particularmente sofisticado, verdadeira materialização do saber (coleções, jardim botânico, plantas raras), em 1937 o parque de Maurepas devia responder às considerações mais higienistas, propondo às crianças das famílias trabalhadoras um espaço de jogo e ar puro. Esta evolução, da representação para a consideração dos usos, se desenvolveu com a urbanização do pós-guerra: os parques contemporâneos, menos demonstrativos, visam criar ambientes propícios a multiplicidade de atividades (RENNES, 2005c, p. 4, tradução e grifo nossos).

A partir desta passagem nota-se que, se antes os parques eram pensados de forma dominante no sentido da sua apresentação, sua ornamentação, passou-se a pensar que apenas este modelo não está mais adaptado à multiplicidade e diversidade de paisagens e formas de usos destes espaços. Somado a isso, o documento apresenta que os esforços “estão centrados na qualificação - ou requalificação - destes espaços, a fim que eles se tornem elementos identificadores de um bairro ou região, lugares de vida, de encontro, de diversidade de usos [...]" (RENNES, 2005d, p.4, tradução nossa).

A partir da descrição dos bairros em que estão inseridas e observando a estrutura, as dimensões e os equipamentos das áreas infantis estudadas, podemos 
estabelecer que existe uma relação entre a área infantil e o bairro/parque onde a mesma se localiza.

Por exemplo, o parque do Thabor, situado em um bairro nobre da cidade, tem uma história de longa data, concebido em uma época em que os costumes com relação à atividade física e mobilidade corporal eram diferentes, sendo criado sobretudo para fins de contemplação. Sua área infantil foi criada apenas na década de 60 , provavelmente em virtude de uma mudança de paradigma com relação ao movimento e ao corpo ${ }^{25}$, além da necessidade de um lugar autorizado para as crianças brincarem, pois na maior parte do gramado não é permitido pisar. Uma das relações possíveis de serem estabelecidas é a de que as limitações com relação ao uso do gramado e a criação de um espaço específico onde as crianças possam brincar pode estar ligada aos fins contemplativos aos quais o parque foi concebido.

O parque de Maurepas, apresenta uma área infantil ampliada em relação às outras áreas pesquisadas, com mais equipamentos, sendo estes também mais diversos. Concebido com fins higienistas, como um espaço de brincar, do jogo e do movimento para as crianças, é fronteiriço a um bairro de essência familiar, grande parte residencial, o que pode justificar uma área infantil de maiores proporções.

Já o parque de Bréquigny, que busca aliar interesses hortícolas com esportivos e de lazer, possui uma área infantil não tão ampla e diversificada quanto à de Maurepas, mas de maiores proporções quando comparada à do Thabor, em virtude do maior espaço disponível. Possui também mais equipamentos destinados às crianças de maior faixa etária, em relação aos demais parques estudados.

\footnotetext{
${ }^{25}$ Segawa (1996) nos mostra que a partir das descobertas médicas a respeito, por exemplo, da circulação sanguínea, a percepção acerca do movimento corporal foi se transformando. Se antes era visto como algo ruim, por estar associado ao trabalho, a partir destas descobertas o movimento do corpo começou a adquirir status de algo que fazia bem a saúde.
} 
Em resposta ao questionário, reiterando algumas destas observações, o gestor nos diz que

\begin{abstract}
A superfície da área infantil pode condicionar os equipamentos de maior ou menor tamanho. Por exemplo, a área infantil do Thabor está fixada em função do plano de origem do parque (1860) e é difícil de a aumentar. O parque de Maurepas esteve previsto desde o começo (1936) com uma zona para as crianças fortemente dimensionada. Em seguida, cada local possui suas particularidades. Alguns espaços têm abrangência de bairro, enquanto outros ocupam perímetros maiores. Desta forma, enquanto o Thabor e o Gayeulles absorvem o público de Rennes Metrópole, o Maurepas e o Bréquigny possuem maior alcance de bairro. Em função disso, os equipamentos podem mudar. Enfim, é interessante propor equipamentos diferentes na cidade a fim de tornar o patrimônio de jogo menos homogêneo. A qualidade lúdica na cidade também aumentou (instalação de uma tirolesa e muro de escalada no parque de Gayeulles em 2013, por exemplo) (RESPOSTA 3 , grifo nosso).
\end{abstract}

A resposta do gestor também nos traz a questão da possibilidade da instalação de determinados equipamentos nas áreas infantis em função da dimensão do espaço e sua localização central ou periférica na cidade. Também a estrutura dos elementos de segurança e organização das áreas infantis estão em consonância com o parque onde estão localizados. Por exemplo, a cerca que delimita equipamentos da área infantil do parque de Maurepas é feita de uma espécie de arame, já a que delimita os balanços na área do parque de Bréquigny é de madeira, em razão das características e localização dos parques (o primeiro em área residencial, o segundo campestre).

É interessante ressaltar a busca pela diversificação dos equipamentos, além da sua necessária conservação, a fim de que a heterogeneidade e ampliação das possibilidades corporais possam dominar entre os equipamentos e brincadeiras das crianças.

Nos parques em geral, verifica-se certa diversidade de usos, permitindo o descanso e a contemplação (com bancos, gramados autorizados, em dois deles áreas de 
piquenique), a realização de práticas físico-esportivas (vias para caminhada/corrida, mesas de ping-pong e pebolim), além das áreas infantis já citadas. No entanto, cada qual com um enfoque predominante em um âmbito diferente, fato que influencia a estrutura da área infantil em cada qual instalada.

\section{Considerações Finais}

Os espaços analisados nesta pesquisa apresentaram em geral uma diversidade de equipamentos, tanto no que se refere aos seus modelos (individuais, coletivos, de escorregar, girar, balançar, multifuncionais) quanto à abrangência das faixas etárias, com equipamentos que atendem dos 2 a 16 anos. Além disso, as áreas infantis atendem às normas regulatórias de segurança do país (piso, espaço do entorno, cercados, placas indicativas) e seus equipamentos demonstraram bom estado de conservação. Também a partir das análises, os modelos, a dimensão das áreas infantis e a quantidade de equipamentos variam de acordo os parques e os objetivos propostos para eles. Existe uma política de gestão para estes espaços, que busca levar em consideração a região onde os mesmos se localizam e a população do seu entorno.

Destaca-se que estas áreas sejam bem estruturadas, pois um lugar seguro, atrativo e diversificado influencia o processo de apropriação, que se faz importante, pois como afirma Marcellino (2006, p.37) “Através do prazer, o brincar possibilita à criança a vivência da sua faixa etária e ainda contribui, de modo significativo, para sua formação como ser realmente humano, participante da sociedade em que vive, e não apenas como mero indivíduo requerido pelos padrões de 'produtividade social'”.

Mesmo que algumas opiniões se mostrem contrárias à existência das áreas infantis, com o argumento de que elas tendem a especializar ou até "engessar" as 
brincadeiras das crianças, hoje se verifica que as áreas infantis constituem um dos poucos espaços públicos garantidos e legitimados para o brincar infantil no contexto das cidades atuais, em que os espaços disponíveis vêm consideravelmente diminuindo, geralmente se tornando vias para carros. Na realidade, o ideal seria que não houvesse apenas um espaço necessariamente destinado às crianças, mas que à criança fosse reservado o direito à cidade como um todo. Como os espaços hoje existentes muitas vezes não dão chances ou oportunidades para elas, as áreas infantis constituem as brechas do brincar infantil nas cidades e por isso estes espaços devem ser o mais atrativo, seguro e dinâmico, a fim de que possam atender ao menos uma parcela das necessidades das crianças.

\section{REFERÊNCIAS}

ASSIS, T. S. de. A privatização no Parque Barigui: possíveis influências na apropriação dos espaços e equipamentos de lazer. 2014. 97 f. Dissertação (Mestrado em Educação Física) - Departamento de Educação Física, Universidade Federal do Paraná, Curitiba, 2014.

FERRONATO, Raquel Franco; BATISTA, Cleide Vitor Mussini. Brincar: um direito de liberdade. Londrina: Eduel, 2013.

GEORENNESMETROPOLE. Plan Intéractive de Rennes (Ville et Metropole) - 2011. Disponível em: $<$ http://www.geo.rennesmetropole.fr/>. Acesso em: 01 nov.2013.

INSEE - Institut National de la Statistique et des Études Économiques (2010). Disponível em: $<$ http://www.insee.fr/fr/themes/tableau local.asp?ref id=POP\&millesime=2010\&ni vgeo $=$ CV\&codgeo $=3598>$. Acesso em: 06 nov. 2013.

JACOBS, J. Morte e vida de grandes cidades. Tradução Carlos S. Mendes Rosa. São Paulo: Martins Fontes, 2000.

L'OUEST ÉCLAIR. Le parc de Maurepas, "Paradis des enfants". Rennes, 26 juillet 1939. Disponível em: <http://gallica.bnf.fr/ark:/12148/bpt6k6616931/f8>. Acesso em: 24 nov. 2013.

MARCELlinO, N. C. Estudos do Lazer: uma introdução. 4. ed. Campinas: Autores Associados, 2006. 
. et al. Espaços e equipamentos de lazer em região metropolitana: o caso da $\overline{\mathrm{RMC}}$ - Região Metropolitana de Campinas. Curitiba: Opus, 2007.

MORO, L. Conhecendo os parques de Curitiba e seus espaços públicos destinados às brincadeiras infantis. 2012. 152 f. Dissertação (Mestrado em Educação Física) Departamento de Educação Física, Universidade Federal do Paraná, Curitiba, 2012.

RECHIA, S. Planejamento dos espaços e dos equipamentos de lazer nas cidades: uma questão de "saúde urbana". In: FRAGA, A. B.; MAZO, J. Z.; STIGGER, M. P.; GOELlner, S. V. (Orgs.). Políticas de lazer e saúde em espaços urbanos. Porto Alegre: Gênese, 2009.

; BÉTRAN, J. O. Parques urbanos de Barcelona: relação entre os usos principais e combinados, a diversidade nas formas de apropriação e a segurança. Movimento, Porto Alegre, v. 16, n. 03, p. 181-202, julho/setembro de 2010.

.; TSCHÖKE, A. O lazer das crianças no bairro Uberaba em Curitiba: a dialética entre os espaços de lazer e a problemática urbana na periferia. Revista Brasileira de Ciências do Esporte, v. 34, p. 01, 2012.

RENNES. Cahier de Prescriptions Générales de L'espace Public - Espaces Verts Livret A (Typologie et Prescrptions Comunnes). 12 novembre 2008a. Disponível em: < http://www.espacepublic.rennes.fr/>. Acesso em: 17 nov. 2013.

RENNES. Prix de la ville ludique 2005. Rennes, 2005b.

RENNES. Guide de Maintenance - La Gestion Differenciée à Rennes. Rennes, 2005c.

RENNES. Plan Local d'Urbanisme. Document I. Rapport de Présentation. 1. Contexte, diagnostic, état initial de l'environnement. P.L.U. approuvé le 17 mai 2004d.

SEGAWA, H. Ao amor do público: jardins no Brasil. São Paulo: Studio Nobel, 1996.

TONUCCI, F. La ciudad de los niños: un modo nuevo de pensar la ciudad. Buenos Aires: Losada, 1996.

TSCHOKE, A. Lazer na infância: possibilidades e limites para vivência do lazer em espaços públicos na periferia de Curitiba/Paraná. 2010. 99f. Dissertação (Mestrado em Educação Física) - Departamento de Educação Física, Universidade Federal do Paraná, Curitiba, 2010.

WRIDT, Pamela J. An Historical Analysis of Young People's Use of Public Space, Parks and Playgrounds in New York City. Children, Youth and Environments. v.14, n. 1, p. 100-120, 2004. 
Aline Tschöke, Luize Moro, Karine do Rocio V. dos Santos,

Emília Amélia Pinto C. Rodrigues e Gabriela C. Machado

\section{Endereço dos Autores:}

Daniella Tschöke Santana

Rua Dionízio Baglioli, ${ }^{\circ}$ 121, bairro Guabirotuba

Curitiba - PR - 81.510-540

Endereço Eletrônico:dani_ellats@hotmail.com

Simone Rechia

Rua Manoel dos Santos da Silva, nº 171 B, bairro São Lourenço

Curitiba - PR - 82.200212

Endereço Eletrônico: simonerechia@hotmail.com

Aline Tschöke

Rua da Bandeira, $n^{\circ} 482$ AP 4b, bairro Cabral,

Curitiba - PR - 80035-270

Endereço Eletrônico: aline_tschoke@yahoo.com.br

Luize Moro

Rua Manoel dos Santos da Silva, nº171 B, bairro São Lourenço,

Curitiba - PR - 82.200212

Endereço Eletrônico: luize.moro@yahoo.com.br

Karine do Rocio Vieira dos Santos

Avenida Brasil, $n^{\circ}$ 2334, bairro Iguaçu

Araucária - PR - 83.701-250

Endereço Eletrônico: karine_ufpr@yahoo.com.br

Emília Amélia Pinto Costa da Silva

Rua João Machado, $n^{\circ}$ 90, bairro Prata

Campina Grande - PB - 58.400-510

Endereço Eletrônico: milapcosta@hotmail.com

Gabriela Cardoso Machado

Rua Doutor Eduardo Mendes Gonçalves, $n^{\circ}$ 508, bairro Bairro Alto,

Curitiba - PR - 82.820-400

Endereço Eletrônico: gabrielacardosomachado@gmail.com 